\title{
Clonality Test by PCR - PARR in Real Time of Canine Lymphomas
}

\author{
Saulo Romero Felix Gonçalves ${ }^{1}$, Francisco de Assis Leite Souza ${ }^{2}$, Pedro Paulo Feitosa de Albuquerque ${ }_{\odot}{ }^{\text {, }}$ \\ Renata Pimentel Bandeira de Melo ${ }_{\odot}^{1} \&$ Andrea Alice da Fonseca Oliveira ${ }_{\odot}^{1}$
}

\begin{abstract}
Background: Lymphoma is a neoplasm of hematopoietic origin that affects canines. The proper establishment of prognosis and rapid institution of treatment are essential for a better quality of life, and immunophenotyping is one of the tools used for this purpose. The objective of this study was to perform a clonality test for immunophenotypic characterization of canine lymphomas using the polymerase chain reaction (PCR) for antigen receptor rearrangements (PARR) technique in real-time from samples fixed in formalin and embedded in paraffin.

Materials, Methods \& Results: The 23 analyzed samples were fixed in formalin and embedded in paraffin canine lymphoma from the collection Laboratory of Histopathology of the Animal Pathology Area of the Departament of Veterinary Medicine Federal Rural University of Pernambuco (UFRPE). Samples were processed, their DNA was extracted, quantified, diluted, and standardized at a concentration of $50 \mathrm{ng} / \mu \mathrm{L}$. After extraction, all samples were subjected to conventional PCR for endogenous control (detection of the IgM target region), in which the extracted DNA was amplified in a final volume of $25 \mu \mathrm{L}$. The 128 bp amplified product was detected by $1.5 \%$ agarose gel electrophoresis. Of the 23 samples analyzed for the detection of the conserved region referring to the endogenous gene, $91.30 \%$ (21/23) amplified the conserved region $\mathrm{C} \mu$ by conventional PCR, and two samples $8.70 \%$ (2/23) were negative. Endogenous control positive samples were subjected to real-time PCR-PARR for detection of IgH Major and IgH Minor for B lymphocytes (LB), and TCRy for lymphocytes T(LT) target regions. All reactions were performed in duplicate to reduce the risk of false-positive or false-negative results due to technical errors. Samples previously confirmed by immunohistochemistry were used as positive controls for T cell and B cell lymphoma, and MilliQ water was used as a negative reaction control. After amplification, the melting curve gradually increased the temperature by $1{ }^{\circ} \mathrm{C} / 5 \mathrm{~s}$ to $95^{\circ} \mathrm{C}$ during continuous fluorescence monitoring. Of the 21 samples analyzed, $100.00 \%(21 / 21)$ demonstrated clonal amplification. Of these, $57.15 \%$ (12/21) were positive for phenotype B, and $42.85 \%(9 / 21)$ were positive for phenotype T.

Discussion: Due to the importance of researching and confirming samples from files fixed and embedded in paraffin samples in laboratories, PCR-PARR is a good tool for this purpose. In the present study, real-time PCR analysis demonstrated greater sensitivity in the characterization of the immunophenotype of lymphomas from old samples fixed in formalin and embedded in paraffin. The temperature of melting curve analysis may vary depending on the amount of DNA and its quality. In the present study, it was found that the average melting temperature in the samples varied between $\pm 3^{\circ} \mathrm{C}$ when compared to that in the control sample for $\mathrm{LB}$ and $\mathrm{LT}, 83.5^{\circ} \mathrm{C}$ and $80^{\circ} \mathrm{C}$, respectively: in the literature, there is a relative difference in this temperature, which may vary up to $4^{\circ} \mathrm{C}$. Real-time PCR-PARR was satisfactory in the characterization of the immunophenotype of canine lymphomas from formalin-fixed and paraffin-embedded samples; therefore, its use is recommended for both retrospective studies. The use of PCR-PARR associated with histopathological and/or cytopathological examination in cases of canine lymphomas strongly helps pathologists, provide a safe establishment of the immunophenotype, minimize errors, and optimize the diagnosis, thus directly contributing to the establishment of the prognosis.
\end{abstract}

Keywords: immunophenotyping, lymphoproliferative disease, real-time PCR, TCR $\gamma$, IgH. 


\section{INTRODUCTION}

Lymphoma is one of the neoplasms that mostly affects dogs, representing approximately $7-24 \%$ of all neoplasms and approximately $83 \%$ of neoplasms of hematopoietic origin $[3,13,17]$. The use of polymerase chain reaction (PCR) for antigen receptor rearrangement (PCR-PARR) has been discussed over the years as a diagnostic tool for this neoplasm $[1,2,10,15]$.

The need to study PCR-PARR is a simple fact that lymphocytes have unique DNA sequences in specific regions, including the CDR3 complementarity determining region in the immunoglobulin regions (IgH Major and IgH Minor) and T cell receptors (TCR) that encode the binding of receptors [6]. CDR3 is produced by the recombination of $\mathrm{V}, \mathrm{D}$, and $\mathrm{J}$ genes and $\mathrm{V}$ and $\mathrm{J}$ genes (TCR $\gamma$ ), in B cell lymphocytes and $\mathrm{T}$ cell lymphocytes, respectively $[2,10]$.

The increase in the diagnosis of canine lymphomas based on sensitive techniques that can act in a complementary way is currently a great challenge, essential in the proper management of the neoplasm, guiding the veterinarian in the most appropriate therapeutic protocol, to offer a better quality of life for animals. Thus, the objective was to perform immunophenotypic characterization using the PCR-PARR technique in real-time on canine lymphomas from samples fixed in formalin and embedded in paraffin.

\section{MATERIALS AND METHODS}

\section{Sampling}

Twenty-three formalin-fixed and paraffinembedded samples of canine lymphomas from the collection of the Laboratory of Histopathology of the Animal Pathology Area of the Department of Veterinary Medicine - Federal Rural University of Pernambuco (DMV-UFRPE) were selected, corresponding to the period from 2008 to 2018, that were previously diagnosed as lymphoma by histopathological analysis, which was the criteria for inclusion of samples in this research.

\section{Extraction of DNA}

DNA extraction was performed at the Laboratory of Infectious Diseases (LDIC) at the DVM-UFRPE. Samples were processed according to the manufacturer's protocol using the ReliaPrepTM FFPE gDNA Miniprep System Promega kit ${ }^{1}$. After extraction, the DNA was eluted in a final volume of $50 \mu \mathrm{L}$. The DNA was quantified at Instituto Aggeu Magalhães, Fundação Oswaldo
Cruz (FIOCRUZ), Recife-PE, using a NanoDrop 2000 Spectrophotometer NanoDrop ${ }^{\mathrm{TM} 2}$, and later diluted and standardized to a concentration of $50 \mathrm{ng} / \mu \mathrm{L}$.

\section{Conventional PCR for endogenous control}

Conventional PCR reactions were performed at the Laboratory of Applied Molecular Animal Physiology (FAMA) of the Department of Animal Morphology and Physiology at UFRPE.

After extraction, all samples were subjected to conventional PCR for endogenous control (detection of the IgM target region) in which the extracted DNA was amplified in a final volume of $25 \mu \mathrm{L}$ containing: $12.5 \mu \mathrm{L}$ of GoTaq Master Mix Green ${ }^{1}, 1 \mu \mathrm{L}$ of each primer set $\mathrm{C} \mu$ at $10 \mathrm{pM}$ (Sigmf1: 5' TTC CCC CTC ATC ACC TGT GA 3' and Sru3: 3' GGT TGT TGA TTG CAC TGA GG 5'), $5.5 \mu \mathrm{L}$ of MilliQ water and $250 \mathrm{ng}$ of DNA $(5 \mu \mathrm{L})$. The thermal profile used was in accordance with the literature [2] as follows: denaturation at $95^{\circ} \mathrm{C}$ for $15 \mathrm{~min}, 35$ cycles of annealing at $94^{\circ} \mathrm{C}$ for $8 \mathrm{~s}$, and $60^{\circ} \mathrm{C}$ for $10 \mathrm{~s}$, with a final extension at $72^{\circ} \mathrm{C}$ for $5 \mathrm{~min}$. The $128 \mathrm{bp}$ amplified product was detected by $1.5 \%$ agarose gel electrophoresis, stained with SYBR Safe (DNA Gel Stain) ${ }^{2}$, visualized under ultraviolet light, and photographed.

\section{Real-time PCR and melting curve analysis (MCA)}

Endogenous control positive samples were subjected to real-time PCR-PARR to detect IgH Major (LB), IgH Minor (LB), and TCR $\gamma$ (LT) target regions. The reactions were carried out in a Rotor-Gene $\mathrm{Q}$ thermocycler ${ }^{3}$ at the FAMA of the Department of Animal Morphology and Physiology at UFRPE.

Real-time PCR for the IgH Major target region had a final volume of $15 \mu \mathrm{L}$, containing: $100 \mathrm{ng}$ of DNA $(2 \mu \mathrm{L}), 1 \mu \mathrm{L}$ of each primer at $10 \mathrm{pM}$ (CB1: 5' CAG CCT GAG AGC CGA GGA CAC 3' and CB2: 3' TGA GGA GAC GGT GAC CAG GGT 5'), $7.5 \mu \mathrm{L}$ of SYBR ${ }^{\mathrm{TM}}$ Green I PCR Master Mix (Applied Biosystems $\left.^{\mathrm{TM}}\right)^{2}$ and $3.5 \mu \mathrm{L}$ of MilliQ water. The thermal profile used was as described by Langner et al. [8]: initial denaturation at $95^{\circ} \mathrm{C}$ for $10 \mathrm{~min}$, followed by 40 cycles of denaturation for $15 \mathrm{~s}$ at $95^{\circ} \mathrm{C}$, annealing for $30 \mathrm{~s}$ at $60^{\circ} \mathrm{C}$ and extension for $30 \mathrm{~s}$ at $72^{\circ} \mathrm{C}$.

Real-time PCR for the IgH Minor target region had a final volume of $15 \mu \mathrm{L}$, containing: $100 \mathrm{ng}$ of DNA $(2 \mu \mathrm{L}), 1 \mu \mathrm{L}$ of each primer at $10 \mathrm{pM}\left(\mathrm{CB} 1: 5^{\prime} \mathrm{CAG}\right.$ CCT GAG AGC CGA GGA CAC 3' and CB3: 3' TGA GGA CAC GAA GAG TGA GG 5'), $7.5 \mu \mathrm{L}$ of SYBR ${ }^{\mathrm{TM}}$ 
Green I PCR Master Mix (Applied Biosystems $\left.{ }^{\mathrm{TM}}\right)^{2}$ and $3.5 \mu \mathrm{L}$ of MilliQ water. The thermal profile was as follows: initial denaturation at $95^{\circ} \mathrm{C}$ for $10 \mathrm{~min}, 40$ cycles of denaturation for $15 \mathrm{~s}$ at $95^{\circ} \mathrm{C}$, and annealing together with extension for $60 \mathrm{~s}$ at $60^{\circ} \mathrm{C}$.

Real-time PCR for the TCR $\gamma$ target region had a final volume of $15 \mu \mathrm{L}$ containing: $100 \mathrm{ng}$ of DNA (2 $\mu \mathrm{L}), 1 \mu \mathrm{L}$ of each primer at $10 \mathrm{pM}$ (TCR $\gamma 1: 5^{\prime} \mathrm{ACC}$ CTG AGA ATT GTG CCA GG 3', TCR 2 : 5' GTT ACT ATA AAC CTG GTA AC 3' and TCR'3: 3' TCT GGG A/GTG TAC/T TAC TGT GCT GTC TGG 5'), $7.5 \mu \mathrm{L}$ SYBR ${ }^{\mathrm{TM}}$ Green I PCR Master Mix (Applied Biosystems $\left.^{\mathrm{TM}}\right)^{2}$ and $2.5 \mu \mathrm{L}$ of MilliQ water. The thermal profile was as follows: initial denaturation at $95^{\circ} \mathrm{C}$ for $10 \mathrm{~min}, 40$ cycles of denaturation for $15 \mathrm{~s}$ at $95^{\circ} \mathrm{C}$, annealing, and extension for $60 \mathrm{~s}$ at $60^{\circ} \mathrm{C}$.

All reactions were performed in duplicate to reduce the risk of false-positive or false-negative results due to technical errors.
As a positive control for $\mathrm{T}$ cell and $\mathrm{B}$ cell lymphoma, samples provided by the VetMol Laboratory (Veterinary Molecular Pathology-Diagnosis and Research, Botucatu, SP), previously confirmed by immunohistochemistry, were used. For polyclonal (reactive) control, a pool of 3 DNA samples from the tonsils of necropsied animals without clinical/ laboratory history of lymphoproliferative disease confirmed by fine-needle aspiration cytology was performed at the Animal Pathology Area of the DMV-UFRPE. Ultrapure water was used as a negative control.

After amplification, the melting curve gradually increased the temperature by $1^{\circ} \mathrm{C} / 5 \mathrm{~s}$ to $95^{\circ} \mathrm{C}$ during continuous fluorescence monitoring. Data were analyzed using Rotor-Gene Q Series Software ${ }^{3}$ [Figure 1]. The evaluation of clonal rearrangement was based on analyses previously described in the literature [8].

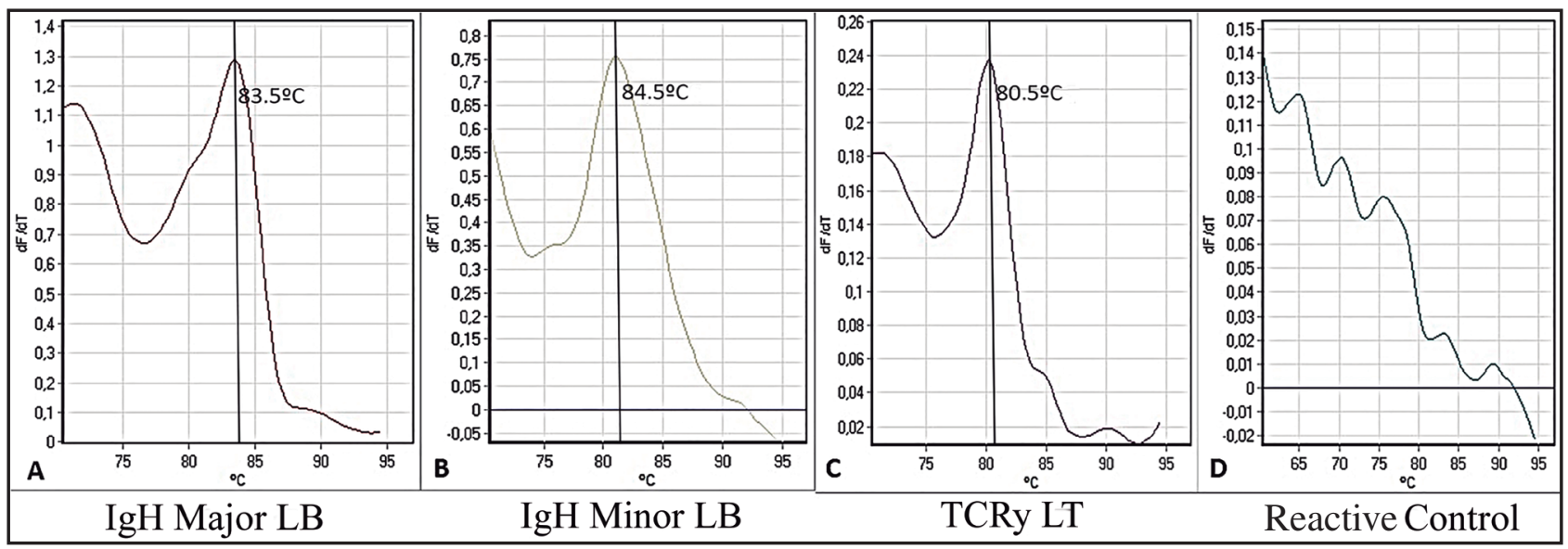

Figure 1. Monoclonal and polyclonal amplification of polymerase chain reaction (PCR) for antigen receptor rearrangement (PCR-PARR) positive control. A- Clonal amplification for $\mathrm{LB}$ is observed in a IgH major gene at a melting temperature of $83.5^{\circ} \mathrm{C}$. B- Clonal amplification for $\mathrm{LB}$ in the IgH minor gene with melting temperature at $84.5^{\circ} \mathrm{C}$. C- Clonal amplification for LT in TCR $\gamma$ gene with melting temperature at $80.5^{\circ} \mathrm{C}$. D- Polyclonal amplification featuring lymphoid reactivity with multiple broad peaks.

\section{RESULTS}

\section{Conventional PCR for endogenous control}

Of the 23 samples analyzed for detecting the conserved region referring to the endogenous gene, $21(91.30 \%)$ amplified the conserved region $\mathrm{C} \mu$ by conventional PCR, and a fragment of 128 bp was observed in the $1.5 \%$ agarose gel (Figure 2). Two samples $(8.70 \%)$ were negative.

\section{Real-time PCR-PARR}

In real-time PCR-PARR, of the 21 samples analyzed, $100.00 \%$ demonstrated clonal amplification. Of the 21 samples with clonal amplification, 12 (57.15\%) were positive for the B phenotype, and $9(42.85 \%)$ were positive for the $\mathrm{T}$ phenotype. In the MCA, they were considered positive when a single, high, symmetrical, and short peak was observed in the fluorescence by real-time $\mathrm{PCR}$, with a melting temperature varying $\pm 3^{\circ} \mathrm{C}$ (Figure 3 ). 


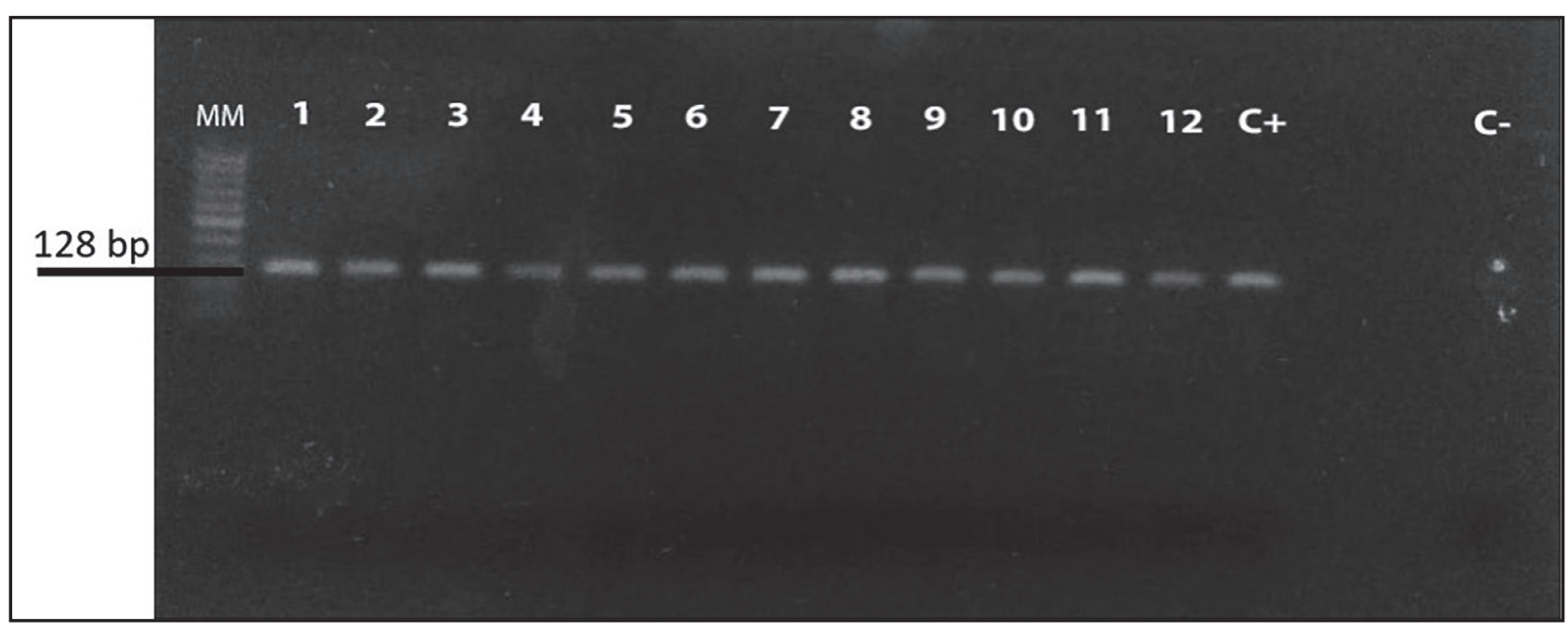

Figure 2. Analysis of the polymerase chain reaction product by 1.5\% agarose gel electrophoresis of the endogenous genes of C $\mu$ lymphocytes. MM: 50 bp DNA ladder (molecular weight); C+: positive control; C-: negative control; lanes 1 to 12: positive samples at 128 bp height.

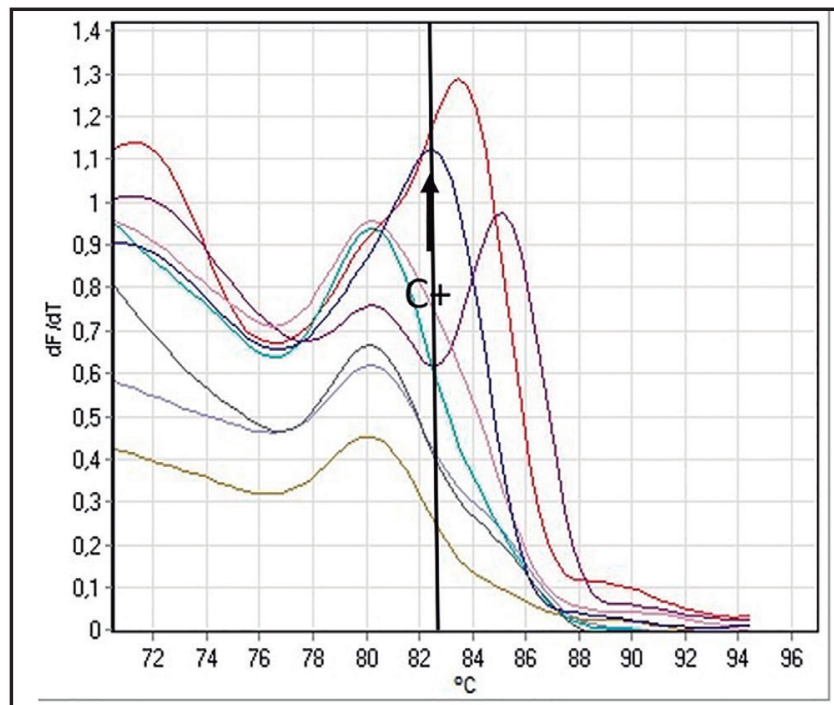

Positive samples for LB

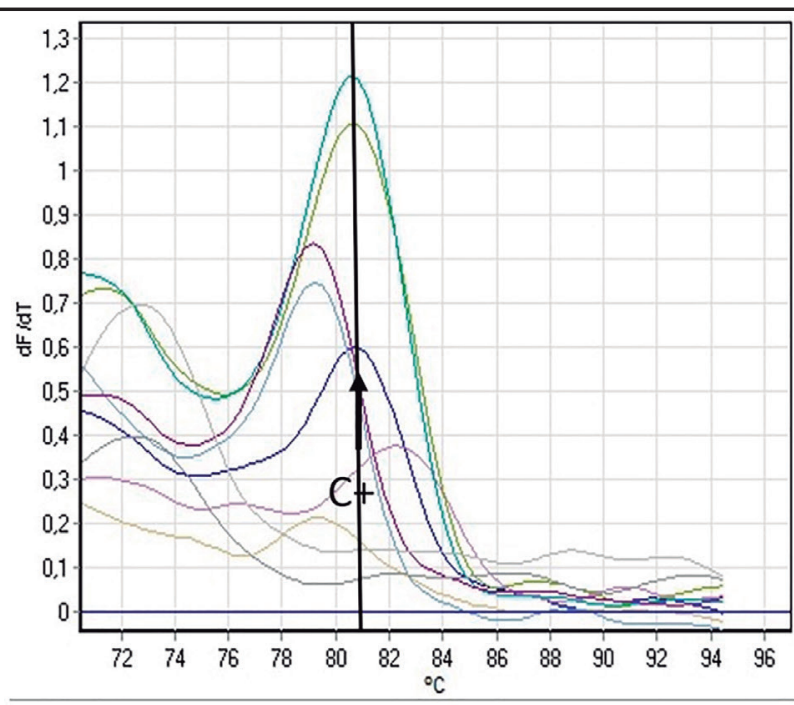

Positive samples for LT

Figure 3. Results of field samples in the real-time polymerase chain reaction. A- Monoclonal amplification in field samples with a single high peak similar to the positive control $(\mathrm{C}+)$ at a temperature of $83.5^{\circ} \mathrm{C}$ with an average melting temperature variation of $\pm 3^{\circ} \mathrm{C}$. $\mathrm{B}$ - Monoclonal amplification in field samples with single and high peaks is similar to the positive control $(\mathrm{C}+)$ at a temperature of $80^{\circ} \mathrm{C}$ with an average melting temperature variation of $\pm 3^{\circ} \mathrm{C}$.

\section{DISCUSSION}

Gene rearrangement studies are widespread in human and veterinary medicine, and these specific lymphocyte cell membrane loci are essential because the conserved regions of CDR3 used for analysis are a product of the recombination of genes $\mathrm{V}, \mathrm{D}$, and $\mathrm{J}$, to obtain the genes TCR $\gamma$ and higher and lower $\operatorname{IgH}$ [2,5-7].

Due to the importance of researching and confirming samples from files fixed and embedded in pa- raffin samples in laboratories, PCR-PARR has become a good tool for this purpose; therefore, it was decided to adopt the use of the conventional PCR-PARR to canine lymphoma immunophenotype for real-time PCR-PARR using primer sets already established in the literature. Four sets of primers were used: $2 \mathrm{IgH}$ and 2 TCR primers [2,15].

It was observed that some samples had a low amount of DNA, which is expected, since the histopathological processing to which the samples 
are submitted, using xylol and formalin, for example, favors the occurrence of DNA lesions, impairs its quality [12], and interferes with the amount of DNA present, generally lower, with no good amplification in conventional PCR $[8,10,15]$.

In the present study, real-time PCR analysis demonstrated greater sensitivity in the characterization of the immunophenotype of lymphomas from old samples fixed in formalin and embedded in paraffin. Samples with less than $0.78 \%$ of DNA can be detected by real-time PCR, obtaining greater sensitivity when compared to conventional PCR; therefore, it is recommended to use PCR-PARR in real-time in laboratories that require a more in-depth study of old samples that do not require a large amount of DNA [8].

To analyze the results obtained in real-time PCR-PARR, it is necessary to understand the MCA, considering what already exists in the literature. [8]. All samples evaluated were considered positive by the MCA, as they presented single, regular, and long peaks, as observed in the literature, when clonal detection of the lymphoma antigen receptor by PCR-PARR in real-time occurs, as opposed to reactive samples that demonstrate multiple broad, short, and polyclonal peaks $[2,10]$.

The temperature of MCA varies depending on the amount of DNA and its quality. In the present study, it was found that the average melting temperature of the samples varied between $\pm 3^{\circ} \mathrm{C}$ when compared to that in the control sample for LB and LT, $83.5^{\circ} \mathrm{C}$ and $80^{\circ} \mathrm{C}$, respectively, and there is a relative difference in this temperature, which may vary up to $4^{\circ} \mathrm{C}$; thus, samples amplified with a single, high, and symmetrical peaks within this temperature range can be considered monoclonal and positive [11].

The results of this study demonstrated a predominance of positive samples for B cell lymphoma (57.14\%) compared to those of T cells $(42.86 \%)$. In immunophenotypic analyses, B cell lymphomas are the most prevalent in domestic animals. Immunophenotyping of 39 canine lymphomas necropsied and biopsied at the Faculty of Veterinary Medicine of Cluj-Napoca (Romania) observed that in $64.10 \%$ of the evaluated cases, there was a predominance of B cell lymphomas [4], which was also observed in the present study by molecular analysis.

Phenotypic differentiation of lymphoma is of paramount importance in patient therapy and progno- sis; dogs with T cell lymphoma have a low response to chemotherapy and have paraneoplastic syndromes such as hypercalcemia, as well as shorter remission and survival times than those in dogs without $\mathrm{T}$ cell lymphoma; molecular analysis can identify traces of another type of lymphoma that can affect dogs, being used for indolent lymphoma, and total remission factor of the disease [16].

Clonality for $\mathrm{B} / \mathrm{T}$ cell lymphoma is rarely observed; however, some authors have reported a cross-line between $\mathrm{T}$ and $\mathrm{B}$ lymphocytes, positive for both clones by immunohistochemistry and PCR, the last technique being performed to confirm lymphoid clonality [9]. This is because the test performed using PCR is considered more sensitive for detection. One of the hypotheses raised for this type of lymphoma is that a chromosomal mutation occurs, causing the exchange of phenotypic receptors; that is, a lymphoma starts as $\mathrm{B}$ cells, and in contact with exogenous factors, it can undergo changes and express a $\mathrm{T}$ phenotype, and clonal detection may occur for techniques, such as immunohistochemistry or both sets of primers by PCR [7,9].

Several previous studies that compared the PCR-PARR technique with conventional immunohistochemistry revealed an agreement of $>85 \%[10,14]$. Therefore, the application of the real-time PCR-PARR technique in the veterinary medical routine proves to be promising, helping the veterinarian in the diagnosis and establishment of the prognosis of canine lymphomas, as well as in retrospective studies to confirm the clonality of lymphomas.

\section{CONCLUSION}

Thus, it was possible to observe a higher frequency of clonal cells in B cell lymphoma in the analyzed samples. Thus, real-time PCR-PARR was satisfactory for the characterization of the immunophenotype of canine lymphomas from formalin-fixed and paraffin-embedded samples; therefore, its use is recommended for both retrospective and routine medical studies.

Real-time PCR-PARR was able to detect DNA amplification and establish $100 \%$ of the phenotyping in samples embedded in paraffin and archived for a period longer than 10 years.

The use of PCR-PARR associated with histopathological and/or cytopathological examination in cases of canine lymphomas strongly helps pathologists, 
provide a safe establishment of the immunophenotype, minimize errors, and optimize the diagnosis, thus directly contributing to the establishment of the prognosis.

\section{MANUFACTURERS}

${ }^{1}$ Promega Corporation. Madison, WI, USA.

${ }^{2}$ Thermo Fisher Scientific. Wilmington, DE, USA.

${ }^{3}$ Qiagen. Germantown, MD, USA.

Funding. This research was supported by Higher Education Personnel Improvement Coordination (CAPES), and Graduate Support Program (PROAP).
Acknowledgments. To the entire animal pathology team in the Pathology Area and the Infectious Diseases Laboratory (LDIC) of the Department of Veterinary Medicine - UFRPE and to the Department of Animal Physiology and Morphology involved in the project.

Ethical approval. This study was authorized by the Ethics Committee on the Use of Animals (CEUA) of Federal Rural University of Pernambuco (UFRPE) under license no. 65/2017.

Declaration of interest. The authors report no conflicts of interest. The authors alone are responsible for the content and writing of the paper.

\section{REFERENCES}

1 Avery A.C. 2012. Molecular diagnostics of hematologic malignancies in small animals. Veterinary Clinics: Small Animal Practice. 42(suppl): 97-110.

2 Burnett R.C., Vernau W., Modiano J.F., Olver C.S., Moore P.F. \& Avery C.A. 2003. Diagnosis of canine lymphoid neoplasia using clonal rearrangements of antigen receptor genes. Veterinary Pathology. 40(1): 32-41.

3 Calazans S.G., Daleck C.R. \& De Nardi A.B. 2016. Linfomas. In: Daleck C.R. \& De Nardi A.B. (Eds). Oncologia em Cães e Gatos. 2.ed. Rio de Janeiro: Roca, pp.633-648.

4 Cora R., Gal A.F., Taulescu M., Tabaran F., Vidrighinescu R., Toma G.C. \& Catoi C. 2017. Immunohistochemical Characterization of Canine Lymphomas. Bulletin of University of Agricultural Sciences and Veterinary Medicine CLUJ-NAPOCA. Veterinary Medicine. 74(2): 149-155.

5 Ishikawa C.C., Ab'Saber A.M., Parra E.R., Lin C.J., Barbas C.S.V. \& Capelozzi V.L. 2007. Imunofenotipagem e rearranjo gênico em doenças pulmonares linfocíticas e linfoproliferativas. Jornal Brasileiro de Pneumologia. 33(6): 625-634.

6 Keller S.M. \& Moore P.F. 2012. Rearrangement patterns of the canine TCR $\gamma$ locus in a distinct group of T cell lymphomas. Veterinary Immunology and Immunopathology. 145(1) 350-361.

7 Lana S.E., Jackson T.L., Burnett R.C., Morley P.S. \& Avery A.C. 2006. Utility of Polymerase Chain Reaction for Analysis of Antigen Receptor Rearrangement in Staging and Predicting Prognosis in Dogs with Lymphoma. Journal of Veterinary Internal Medicine. 20(2): 329-334.

8 Langner K.F.A., Joetzke A.E., Nerschbach V., Eberle N., Schuberth H.J., Koy M., Nolte I. \& Betz D. 2014. Detection of clonal antigen receptor gene rearrangement in dogs with lymphoma by real-time polymerase chain reaction and melting curve analysis. BMC Veterinary Research. 10(1): 1-5.

9 Nicoletti A., Aresu L., Marino M., Massaro M., Martignani E., Caporali E., Capuccini S., Bonfanti U. \& Gola C. 2020. CD3-CD20-positive nodal lymphoma with cross-lineage rearrangement in a dog. Journal of Veterinary Diagnostic Investigation. 32(6): 1-4.

10 Nowosh V., Macieira D.B. \& Alencar N.X. 2017. Aplicability of PCR-based clonality assay in dogs with multicentric lymphoma. Arquivo Brasileiro de Medicina Veterinária e Zootecnia. 69(3): 761-765.

11 Schöpper I., Ohmura S., Rütgen B., Tsujimoto H., Weber K. \& Hirschberger J. 2016. Melting curve analysis in canine lymphoma by calculating maximum fluorescence decrease. Veterinary and Comparative Oncology. 15(2): 563 575.

12 Thilakaratne D.N., Mayer M.N., MacDonald V.S., Jackson M.L., Trask B.R. \& Kidney B.A. 2010. Clonality and phenotyping of canine lymphomas before chemotherapy and during remission using polymerase chain reaction (PCR) on lymph node cytologic smears and peripheral blood. Canadian Veterinary Journal. 51(1): 79-84.

13 Vail D.M. \& Young K.M. 2007. Hematopoietic tumors. In: Withrow S.J. \& Vail D.M. (Eds). Small Animal Clinical Oncology. 4th edn. St. Louis: Saunders, pp.699-784. 
14 Valli V.E., Bienzle D. \& Meuten D.J. 2017. Tumors of the Hemolymphatic system. In: Meuten D.J. (Ed). Tumors in Domestic Animals. 5th edn. Ames: Iowa State Press, pp.203-321.

15 Waugh E.M., Gallagher A., Haining H., Johnston P.E.J., Marchesi F., Jarrett R.F. \& Morris J.S. 2016. Optimisation and validation of a PCR for antigen receptor rearrangement (PARR) assay to detect clonality in canine lymphoid malignancies. Veterinary Immunology and Immunopathology. 182(2016): 115-124.

16 Yau P., Dhand N.K., Thomson P.C. \& Taylor R.M. 2017. Retrospective study on the occurrence of canine lymphoma and associated breed risks in a population of dogs in NSW (2001-2009). Australian Veterinary Journal. 95(5): 149-155.

17 Zanini D.A., Kimura K.C., Nishiya A.T., Ubukata R., Leandro R.M., Brito C.P., Trombetti M., Lagoa A.C., Macedo T.R., Rodrigues L.C.S., Rosendo J.A.S., Arndt H.L., Dias R.A. \& Dagli M.L.Z. 2013. Environmental risk factors related to the development of canine non-Hodgkin's lymphoma. Ciência Rural. 43(7): 1302-1308. 